and voltage-dependent depression of Vmax was studied in guinea-pig ventricular muscle perfused with Tyrode solution by using conventional microelectrode technique.

The resting block (time-independent block of Vmax) of Quinidine $(0.01 \mathrm{mM})$ was facilitated in a concentration-dependent manner $(0.03 \mathrm{mM}-1 \mathrm{mM})$. Quinidine produced depression of Vmax in a ratedependent manner (RDB was seen under inter-stimulous interval $4800 \mathrm{~ms}$ and was enhanced with the increase of inter-stimulous interval $4800 \mathrm{~ms}$ to $250 \mathrm{~ms})$, and it was facilitated by sodium salicylate in a concentration-dependent manner. The rate of onset of quinidine plus sodium salicylate's RDB ( $2.42 \pm 0.3$ beats) became faster than before (Ton $=3.30 \pm 0.6$ beats).

Quinidine depressed Vmax in more depolarized membrene and this was attributed to the negative shift of the curve relating Vmax to the resting potential along the voltage axis, and the more negative shift was produced by sodium salicylate. It is suggested that the facilitatory effect of sodium salicylate on quinidine-induced fast $\mathrm{Na}^{+}$ channel block was seen not only normal resting potential, but depolarized potential induced by a certain condition such as ischemic state of the heart.

\section{$-180-$ \\ INHIBITORY EFFECTS OF MEXILETINE AND LIDOCAINE ON THE CALCIUM CURRENT OF SINGLE VENTRICULAR MYOCYTES}

Arita

Katsushige Ono, Tatsuto Kiyosue, Makoto

Department of Physiology, Medical College of Oita, Oita 879-56

We studied the effects of the class I-b antiarrhythmic agents, lidocaine (Lido) and mexiletine (Mex), on the calcium current of the guinea pig single ventricular myocytes using tight-seal whole-cell voltage and current clamp. Firstly the effects on action potential duration (APD) were examined. Mex $(30 \mu \mathrm{M})$ significantly shortened the APD by 38\%; Lido also shortened the APD, but the shortening was not statistically significant. In voltage clamp experiment, Mex at the concentrations of 10, 30 and $10 q \mu \mathrm{M}$ decreased $I_{\mathrm{Ca}}$ by 23.0, 29.0 and 55.48, respectively, while Lido decreased it by only $8.9,16.8$ and 25.28 . Inward rectifier $\mathrm{K}$ current $\left(I_{K 1}\right)$ and voltage and time dependent $K$ current $\left(\mathrm{I}_{\mathrm{K}}\right)$ were not changed. At all concentrations tested, a potency of $\mathrm{I}_{\mathrm{Ca}}$ inhibition by Mex was significantly greater than that of Lido $(p<0.05)$. The maximum inhibition $\left(I_{\max }\right)$ and apparent dissociation constant $\left(K_{d}\right)$ were calculated from dose-responce relationship. $I_{\max }$ and $\mathrm{K}_{\mathrm{d}}$ were 70.08 and $34.4 \mu \mathrm{M}$ for $\mathrm{Mex}$ and 328 and 27.4 $\mathrm{M}$ for Lido. The findings suggest that Mex has a greater "efficacy" in blocking the Ca channels, albeit there's little difference in the "affinity" of the two drugs. The main anti-arrhythmic effect of these drugs would be a blockade of the sodium channel. However, the difference in the potency of Ca-antagonism is important to explain the alleged difference in the eligibility to suppress some clinical ventricular arrhythmias.
$-181-$

BLOCKING EFFECTS OF CESIUM AND BARIUM ON THE INWARD-RECTIFIER K CHANNEL IN THE VENTRICULAR CELL MEMBRANE OF THE GUINEA-PIG

\author{
Yoshihisa Kurachi \\ The 2nd Dept of Int Med, \\ Univ of Tokyo, Tokyo
}

It is known that both $\mathrm{Cs}$ and $\mathrm{Ba}$ block $i_{K}$ current and depolarize the resting mem-K brane. With depolarization, Ba causes spontaneous automaticity, but Cs did not. To elucidate the differences in the effects of $\mathrm{Cs}$ and $\mathrm{Ba}$ on $\mathrm{i}_{\mathrm{K}}$, effects of these two ions on the inward-rectifier $k$ channe1 ( $I_{\text {Kre }}$ ) were examined using "ce11at ached" Krech clamp technique. Enzymatically dispersed cells from the guinea-pig ventricle were used. In the single channel current, both $\mathrm{Cs}$ and $\mathrm{Ba}$ blocked I more strongly with higher concentrations of ions and with hyperpolarizing the membrane. The blocking kinetics of Cs were much faster than those of Ba. From the kinetic analyses, it was shown that $\mathrm{Ba}$ binds the site in the channel which senses 0.46 of the membrane potential. In the case of Cs, the value was 1.57 , which suggests that Cs blocks the channel cooperatively with $K$. Furthermore, analyses of burst kinetics and ensemble averaged current disclosed that Cs blocks the channel only in its open state and that Ba blocks it independent $1 y$ from the control kinetics of the channe1. Therefore, it was concluded that $C s$ and $B$ a block I by binding different sites of the channel with different kinetics.

\section{$-182-$ \\ DUAL EFFECT OF METHYLXANTHINES ON THE TRANSIENT INWARD CURRENT OF SHEEP PURKINJE FIBERS}

Junichi Hasegawa*, Hiroto Mashiba*, Hiroyasu Satoh $\star \star$ and Mario Vassalle $\star \star \star$.

*1st Dept. of Int. Med., Tottori Univ. Sch. of Med. $\star \star$ Dept. Of Pharmacol., Yamanashi Med. Coll. $\star \star \star$ Dept. of Physiol., Downstate Med. Ctr., State Univ. of New York.

The actions of different concentrations of caffeine, theophylline and aminophylline on the transient inward current (TI) were studied in sheep purkinje fibers by means of a two microelectrode voltage clamp method.

The following results were obtained. At a low concentration (1 mM), caffeine: 1 ) induced a $T I$ when this currént was not already present; 2) increased the amplitude and decreased the time to peak of an already present $T I$; 3) shifted the depolarizing threshold for the appearance of $T$ to more negative and the repolarizing threshold to less negative values; 4) increased the effect of low concentration of strophanthidin on $\mathrm{TI} ; 5)$ exaggerated the effects of high calcium solutions on TI; 6) enhanced the effects of trains of clamps and of longer clamp steps on TI. At a high concentration $(8 \mathrm{mM})$, caffeine abolished $T I$. Intermediate concentration of caffeine had intermediate effect on TI. Theophylline and aminophylline had actions similar to those of caffeine.

It is concluded that methylxanthines suppress TI

Japanese Circulation Journal Vol. so, June 1986 